\title{
Disaster Knowledge and Household Preparations of Selected Communities in Central Luzon, Philippines: Basis for Enhanced Community Disaster Education Program
}

\author{
John Mark R. Asio ${ }^{1}$ \\ ${ }^{1}$ Social Sciences and Philosophy Department, Faculty of College of Education, Arts \\ and Sciences, Gordon College, Olongapo City, Philippines.
}

Article History

Received:

28.08.2020

Revised:

21.09.2020

Accepted:

29.09.2020

*Corresponding Author:

John Mark R. Asio

Email:

asio.johnmark@gmail.com

This is an open access article, licensed under: $\mathrm{CC}-\mathrm{BY}-\mathrm{SA}$

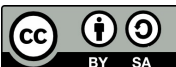

Abstract: Disaster is nature's worst event that can happen anytime and anywhere. It creates unfathomable destruction to everything. This study aimed to analyse and explore the disaster knowledge and household preparations of individuals in selected communities located in Central Luzon, Philippines. The study used a descriptive research design with the survey as the primary data gathering tool. One hundred thirty (130) respondents took part in the survey from two identified communities in Central Luzon using purposive sampling technique. This study also adopted and modified a research instrument which was subjected to validity and reliability test. The researcher subjected the data gathered with the following statistical tools: weighted mean, t-test, ANOVA and Pearson-r with the help of SPSS 20. The study then generated the following findings (1) the respondents were "knowledgeable" about disasters and the households were "prepared" in time of a disaster. In addition, there was a significant difference in the disaster knowledge respondents when grouped according to the community. Also, there exists a relationship between the community of the respondents and their disaster knowledge. Furthermore, a moderate and direct relationship also exists between disaster knowledge and household preparations. Based on the findings the researcher provided a suggestion for an enhanced community disaster education program.

Keyword: Community, Disaster Knowledge, Education Program. 


\section{Introduction}

Cyclones, floods, earthquakes, tsunami, fire, landslides, drought, diseases are some occurring phenomena many individuals consider that as a disaster or calamity. Preparation for such occurrences is very vital and can lead to a matter of life and death situation. The Philippines is a country with a burden of calamity. We can also locate the country in the Pacific Ring of Fire where earthquakes, tsunamis, and volcanic eruptions can occur. Thousands of lives are always at stake, and, it destroys millions and billions of money if it strikes.

The study intended to analyze and explore the disaster knowledge and household preparations of individuals living in selected communities in Central Luzon, Philippines. From this perspective, pertinent individuals and the community can use the generated data and information for other disasterrelated agenda. The researcher wanted to promote a disaster-empowered community by establishing baseline information through this research. To create a disaster resilient individual for the future. Since they are dealing with a natural phenomenon, coping up with such an event is a task that needs ample time and effort.

\section{Literature Review}

The Philippines stands as one of the most disaster-prone areas in the world [1]. Storm and typhoonrelated events account for a significant number of deaths; people affected and losses in assets. However, the country also experiences other geological and hydro-meteorological hazards and other human-induced hazards that contribute to the disasters [2]. Considering such an event, legislators created Republic Act No. 10, 121 also known as the Philippine Disaster Risk Management Act of 2010. This law provides a definite plan for disaster risk reduction and management for every individual. The researcher identified several perspectives to help contextualize and give justice to the current study. Awareness and preparedness are two descriptive words that are almost synonymous in terms of disaster. As stated, awareness plays a significant role to prepare for an impending calamity [3] [4] [5]. Likewise, experience predicts preparedness behaviors [6] [7]. However, some authors disputed some of the notions shared regarding the aforementioned concept [8] [9].

In terms of local knowledge, a great number of authors dedicated their time to providing substantial information significant in this current study. It ranges from written accounts [10] [11], oral narratives [12], local materials and methods [13] to cultural ways [14]. However, the revelation that indigenous knowledge in schools and training programs with various stakeholders have different characteristics and challenges, and they could transfer it from generation to generation [15]. It is also important to recognize that indigenous knowledge should be adaptable, transferable, and changed [16]. An important reminder for every community to recognize the capability of local knowledge in establishing a fundamental awareness tested through time, which proves to be effective and saves countless lives.

Considering the ideas of governance, and traditional community resilience and practices were highlighted [17] [18] [19] to be substantial contributing factors. Close ties, environmental governance, and the interplay between endurance and resilience [20] [21] [22] create a harmonious relationship between people and its counterparts like the government and other players that play an important role for the empowerment of the individuals. How community resilience persists in times of actual disaster wherein effective use and coordination of community resources [23] played a vital role in the fast recovery of individuals. Overall, we can deduct from the lists of reviewed related literature that contrasting features were observed depending on the crisis that have occurred. Nonetheless, the researcher would like to highlight the resilience and indigenous knowledge and adaptation processes that indigenous people possess in terms of survival and coordination from every aspect of disaster mitigation. Finally, an adaptation of such knowledge is also practical, especially in the local setting of this study since the lack of necessary resources also plays a role, and surviving is an essential aspect of the populace. A disaster is an inevitable event that can happen anytime and anywhere, we are all part of it, and the only thing that we need to understand it is how to deal with it and not to turn away our backs since we cannot run away from it.

\section{Methodology}

\subsection{Research Design}

In this study, the researcher used a descriptive research with survey as the main instrument. The main goal of descriptive research is to describe the data and its characteristics [24]. Further, when a 
researcher intends to gain a better perspective of a topic, this is the best type of research. Since the researcher is trying to describe and analyze the knowledge and household preparations regarding disaster of respondents, this study should use the descriptive method to analyze the data.

\subsection{Respondents}

The respondents of the study involve those individuals living in two selected communities in Central Luzon, Philippines. Using a purposive sampling, one hundred thirty (130) individuals took part in the survey. The researcher chose two communities wherein reported cases of disaster is prevalent. For some unforeseen circumstances and the availability of the respondents for whatever reason they have, it was difficult to achieve the sample population for the study. The vicinity of the households also made it harder to reach them, and others were not interested at all. (See Table 1)

Table 1. Respondents of the Study

\begin{tabular}{ccc}
\hline Location & Frequency & Percentage \\
\hline Community A & 55 & 42 \\
Community B & 75 & 58 \\
\hline Total & $\mathbf{1 3 0}$ & $\mathbf{1 0 0}$
\end{tabular}

\subsection{Instrument of the Study}

The research instrument for this study was an adopted and modified survey questionnaire using the REACH Initiative [25], a research NGO based on Geneva as a guide together with other exhaustive review of related literature. The questionnaire was pretested to 25 individuals who are not part of the study. We established the reliability of the test using the test-pretest method and an Alpha Cronbach test of internal validity.

The researcher also subjected the questionnaire to any misunderstood words, phrases, or terms for clarification.

\subsection{Statistical Analysis}

The researcher used several statistical treatments to examine the disaster knowledge, level of awareness on disaster impacts and household preparations of the respondents. They include frequency count, percentage, weighted mean, t-test, ANOVA and Pearson-r. After gathering data, the information was then tallied, tabulated, classified, analyzed, and interpreted. For the computation of necessary statistical treatment of the data, the researcher used Statistical Package for Social Sciences (SPSS) 20.

An informal interview follows to validate some inconsistencies on the respondent's answers and clarifies some misconceptions and ambiguity to their answers.

\section{Finding and Discussion}

\subsection{Finding}

The intention of this study is to analyze the disaster knowledge, level of awareness on disaster impacts, and level of household preparations of individuals in selected communities of Central Luzon, Philippines. The study presented the following findings based on the gathered data in the survey.

Table 2 showed the level of disaster knowledge of respondents living in selected disaster-prone areas. Indicator 3, got the highest weighted mean among the five major indicators with a score of 2.96, which is interpreted as knowledgeable on the Likert scale. Indicator 5 got the lowest weighted mean with a score of 2.12 interpreted as moderately knowledgeable.

On the general, the overall average weighted mean was 2.84 , and this has an interpretation of knowledgeable. This only means that, the respondents have enough knowledge in terms of disaster in their place since they have already experienced some mentioned disasters from time to time.

Table 3 represented the household preparations of the respondents. Item 1 generated highest weighted mean with 2.95 and is translated as prepared in the scale, and the lowest weighted mean belonged Item 3 with 2.58 , which is interpreted in the scale as prepared. 
Table 2. Level of Disaster Knowledge

\begin{tabular}{lcc}
\hline Indicators & WM & Interpretation \\
\hline 1) Awareness of the different kinds/ types of disasters & 2.81 & Knowledgeable \\
2) Familiarity of the types of disasters (storm, earthquake, & & \\
tsunami, diseases, etc.) & 2.87 & Knowledgeable \\
3) The main causes of disasters & 2.96 & Knowledgeable \\
4) Do the main causes of disasters affect your area? & 2.69 & Knowledgeable \\
5) Existence of a Risk reduction priority in the area & 2.12 & Moderately Knowledgeable \\
\hline Average & $\mathbf{2 . 8 4}$ & Knowledgeable \\
\hline
\end{tabular}

*Legend: $\quad$ 1.00-1.49=Not Knowledgeable

1.50-2.49= Moderately Knowledgeable

2.50-3.49=Knowledgeable

3.50-4.00=Very Much Knowledgeable

Overall, the average weighted mean on the level of awareness on household preparations of the respondents are fixed at 2.78 , and we translate this as prepared in the Likert scale. This result assumes that the respondents are alert in their households when a disaster is coming; thus, certain preparations should be done beforehand.

Table 3. Level of Household Preparation

\begin{tabular}{llc}
\hline Indicators & WM & Interpretation \\
\hline $\begin{array}{l}\text { 1) Steps that the family take if there is a disaster forecast } \\
\text { (Evacuation procedures, Securing important things etc.) }\end{array}$ & 2.95 & Prepared \\
2) Household emergency supplies (Food supply, clothing, \\
$\begin{array}{l}\text { contacts, documents, etc.) } \\
\text { 3) Designated Evacuation place (e.g. shelter, church, covered } \\
\text { court/ plaza, school, etc.) }\end{array}$ & 2.76 & Prepared \\
4) Reasons for non-evacuation after a disaster forecast (e.g. \\
safety, financial matters, time, security, etc.) & 2.58 & Prepared \\
5) Possible individual(s)/ group(s) to reach out for help (e.g. & 2.78 & Prepared \\
friends, neighbors, relatives, etc.) & 2.75 & Prepared \\
\hline Average & $\mathbf{2 . 7 8}$ & Prepared \\
\hline & & \\
*Legend: & & \\
$\quad \begin{array}{l}1.00-1.49=\text { Not Prepared } \\
1.50-2.49=\text { Moderately Prepared } \\
2.50-3.49=\text { Prepared } \\
3.50-4.00=\text { Very Much Prepared }\end{array}$
\end{tabular}

Table 4 presented the significant differences in the disaster knowledge, level of awareness on disaster impacts ad level of household preparations of the respondents. Based on the information, there was a significant difference observed in the disaster knowledge of respondents when grouped according to community, since $t(128)=-2.631, p=.010$ which is lower than the alpha significance level of .05. In terms sex, age, and family members, there were no significant finding in both the disaster knowledge and household preparations of the respondents.

This is so since all of the yielded values were higher than the alpha significance level of .05. This further means that regardless of sex, age and family members, the disaster knowledge and household preparations of the respondents do not vary that much. 
Table 4. Significant Differences in the Respondents' Disaster Knowledge and Household Preparations

\begin{tabular}{ccc}
\hline & Disaster Knowledge & Household Preparations \\
\hline $\begin{array}{c}\text { Community } \\
(\mathrm{df}=128) \\
\text { Sex } \\
(\mathrm{df}=128) \\
\text { Age } \\
(\mathrm{df}=3,126) \\
\text { Family Members } \\
(\mathrm{df}=2,127)\end{array}$ & $-2.631^{*}$ & -0.243 \\
$* p<.05$ & 0.504 & 1.109 \\
& 1.016 & 0.132 \\
& 1.509 & 1.513 \\
\hline
\end{tabular}

Table 5 presented the correlation matrix between respondent's profile, disaster knowledge and household preparations of the respondents. Based on the results, the community relates to the disaster knowledge since it got a result of $\mathrm{r}=.226$ which has a corresponding $p$ value of .010 . On the other hand, the disaster knowledge also had a moderate and direct correlation with the household preparations of the respondents, since it yielded a result of $\mathrm{r}=.523$ with a corresponding $p$ value of .000 .

This means that the community that the respondents live in, knowledge about disasters and household preparations have significant links to each other. For example, if one has enough knowledge regarding disaster one can prepare beforehand, thus, preventing damage to household or loss of life.

Table 5. Correlation Matrix between Respondent's Profile, Disaster Knowledge and Level of Household Preparations

\begin{tabular}{lcccccc}
\hline & $\mathbf{1}$ & $\mathbf{2}$ & $\mathbf{3}$ & $\mathbf{4}$ & $\mathbf{5}$ & $\mathbf{6}$ \\
\hline Community & 1 & & & & & \\
Sex & -.042 & 1 & & & & \\
Age & $-.189^{*}$ & -.013 & 1 & & & \\
Family Members & $-.205^{*}$ & -.012 & .066 & 1 & & \\
Disaster Knowledge & $.226^{*}$ & -.044 & -.068 & -.015 & 1 & \\
Household Preparation & .021 & -.098 & .027 & -.015 & $.523^{*}$ & 1 \\
\hline
\end{tabular}
$* p<.05$

\subsection{Discussion}

Disaster knowledge is important for decision making to be more accurate and substantial. For the study, the respondents produced an overall average of knowledgeable amongst the indicators and items of the survey. This means that the respondents are keen on knowing their environment. A keen perspective about the environment [26] is essential yet participation can be limited due to different reasons. In addition, traditional knowledge all over the world, not only needs to be recognized, conserved and documented but also integrated into effective disaster management strategies [27]. However, there are vulnerable people that are not aware of the link between climate and land-use change [7]. This could definitely pose a problem to the community yet manageable to some extent.

For the household preparations, it is just for everyone, regardless of status and standing in life, should prepare for different disasters to come since we are part of an ecosystem that changes from time to time. The study generated an overall result of prepared on the aspect of household preparations. Risk perception, severity of disaster experiences, and community disaster preparedness predicts the disaster preparedness behavior of individuals [6]. It was also found in a study that there are existing analytical frameworks for the interactions between natural disasters, household poverty, 
and household coping strategies in the Philippines [29]. In addition, another study mentioned that community often practice preparedness in terms of earthquakes, typhoons, landslides, and others. [33]

Deeper insights for the study need a deeper understanding. Statistical treatments showed some interesting results from this study. There is a significant difference in the disaster knowledge of the respondents when grouped according to community. Parallel to the result of the study is a paper which reported several factors that prevent useful and timely institutional preparedness and response to disasters [5]. Contrasting lifestyles have implications on the vulnerability and adaptation to climate impacts of their respondents [28]. In addition, there was no statistically significant gender-based difference in disaster knowledge, disaster readiness, disaster awareness and disaster risk perception of the surveyed people in the locality of Nepal [30] and other variables in disaster management [31]. Furthermore, it was found that the personal evaluations' respect for the overall community is the most important [3].

In terms of relationships, the study found out that the community where the respondents lived in and disaster knowledge had a low and direct relationship. In addition, disaster knowledge has a moderate and direct relationship with the household preparations. These results coincide with the studies of Huda [32] and Espina and Calleja [6] which gives us a more varied perspective of disaster relationships with other pertinent factors.

Based on the findings of the study, the researcher strongly suggests an enhanced community disaster education program for both of the communities involved in the study. This is to establish and motivate the communities in preparing for an impending disaster event. Furthermore, this will also alleviate the problems of the local government units in providing necessary information drive before, during and after a disaster event. It will save lives, protect what is important to each and every one, and lessen the burden of loss.

\section{Conclusion}

The respondents were knowledgeable about the different disasters and are prepared in their own households. There was significant difference in the disaster knowledge when the respondents are grouped according to community. Also, there was a relationship between the community of that the respondents lived in and their disaster knowledge. On the other hand, disaster knowledge also correlates with household preparations directly.

\section{References}

[1] NDRRM Plan 2011-2028, National Disaster Risk Reduction and Management Council (NDRRMC), vol. 1 2015. [Online]. Available: https://www.ndrrmc.gov.ph/attachments/ article/41/ NDRRM_Plan_2011-2028.pdf. [Accessed: January 2020].

[2] National Disaster Risk Reduction and Management Council (NDRRMC). [Online]. Available: http://www.ndrrmc. gov.ph/index.php?option=com_content. [Accessed: January 2020].

[3] G. Roder, T. Ruljgaljig, C. -W. Lin, and P. Tarolli, "Natural hazards knowledge and risk perception of Wujie indigenous community in Taiwan," Natural Hazards, vol. 81, pp. 641-662, 2016. [Online]. Available: https://doi.org/10.1007/s11069-015-2100-4. [Accessed: January 2020].

[4] R. M. Mercado, "People's rsk perceptions and responses to climate change and natural disasters in BASECO compound, Manila Philippines," Procedia Environmental Sciences, vol. 34, pp. 490-505, 2016. [Online]. Available: https://doi.org/10.1016/j.proenv.2016.04.043. [Accessed: January 2020].

[5] A. Madan and J. K. Routray, "Institutional framework for preparedness and response of disaster management institutions from national to local level in India with focus on Delhi," International Journal of Disaster Risk Reduction, vol. 14, no. 4, pp. 545-555, 2015. [Online]. Available: https://doi.org/10.1016/j.ijdrr.2015.10.004. [Accessed: January 2020].

[6] E. Espina and M. T. Calleja, "A social cognitive approach to disaster preparedness," Philippine Journal of Psychology, vol. 48, no. 2, pp. 161-174, 2014. [Online]. Available: https://archium.ateneo.edu/ psychology-faculty-pubs/85/. [Accessed: January 2020].

[7] L. A. Acosta, E. A. Eugenio, P. B. M. Macandog, D. B. M. Macandog, E. K. H. Lin, E. R. Abucay, A. L. Cura, and M. G. Primavera, "Loss and damage from typhoon-induced floods and landslides in the Philippines: community perceptions on climate impacts and adaptation 
options," International Journal of Global Warming, vol. 9, no. 1, pp. 33-65, 2016. [Online]. Available: https://doi.org/10.1504/ IJGW.2016.074307. [Accessed: January 2020].

[8] S. N. A. Codjoe, G. Owusu, and V. Burkett, "Perception, experience, and indigenous knowledge of climate change and variability: The case of Accra, a sub-Saharan African city," Regional Environmental Change, vol. 14, pp. 369-383, 2014. [Online]. Available: https://doi.org/10.1007/s10113-013-0500-0. [Accessed: January 2020].

[9] K. E. McNamara and S. S. Prasad, Coping with extreme weather: Communities in Fiji and Vanuatu share their experiences and knowledge. Climatic Change, vol. 123, pp. 121-132, 2014. [Online]. Available: https://doi.org/10.1007/s10584-013-1047-2. [Accessed: January 2020].

[10] N. G. Iloka, "Indigenous knowledge for disaster risk reduction: An African perspective," JAMBA Journal of Disaster Risk Studies, vol. 8, no. 1, pp. 272, 2016. [Online]. Available: https://doi.org/10.4102/jamba.v8i1.272. [Accessed: January 2020].

[11] F. V. Aguilar, "Disaster as contingent events volcanic eruptions, state advisories, and public participation in the twentieth-century Philippines," Philippine Studies: Historical \& Ethnographic Viewpoints, vol. 64, no. 3-4, pp. 593-624, 2016. [Online]. Available: https://www.jstor.org/stable/26621943. [Accessed: January 2020].

[12] S. Janif, P. Nunn, P. Geraghty, W. Aalbersberg, F. Thomas, and M. Camailakeba, "Value of traditional oral narratives in building climate-change resilience: Insights from rural communities in Fiji," Ecology and Society, vol. 21, no. 2, pp. 7, 2016. [Online]. Available: http://www.jstor.org/stable/26270365. [Accessed: January 2020].

[13] L. Hiwasaki, E. Luna, Syamsidik, and J. A. Marcal, "Local an indigenous knowledge onclimate-related hazards of coastal and small island communities in Southeast Asia," Climatic Change, vol. 128, pp. 35-56, 2015. [Online]. Available: https://doi.org/10.1007/s10584-0141288-8. [Accessed: January 2020].

[14] S. N. M. Dalisay, "Engaging local knowledge for disaster risk reduction," Kasarinlan: Philippine Journal of Third World Studies, vol. 29, no. 2, pp. 75-102, 2014.

[15] T. Izumi, and R. Shaw, "Civil society and knowledge, education and training in risk reduction," in Shar R., Izumi, T. (Eds) Civil Society Organization and Disaster Risk Reduction, Disaster Risk Reduction (Methods, Approaches and Practices). Springer, Tokyo, 2014. [Online]. Available: https://doi.org/10.1007/978-4-431-54855-5_7. [Accessed: January 2020].

[16] Syafwina, "Recognizing indigenous knowledge for disaster management: Smong, earlywarning system from Simeulue Island Aceh," Procedia, Environmental Science, vol. 20, pp. 573-582, 2014. [Online]. Available: https://doi.org/10.1016/j.proenv.2014.03.070. [Accessed: January 2020].

[17] M. -F. Fan, "Disaster governance and community resilience: reflections on Typhoon Morakot in Taiwan," Journal of Environmental Planning and Management, vol. 58, no. 1, pp. 24-38, 2015. [Online]. Available: https://doi.org/10.1080/09640568.2013.839444. [Accessed: January 2020].

[18] J. Paulrj, and J. Andharia, "Resilience of indigenous peoples to disasters: An exploration of practices of Konyak community, Nagaland," European Scientific Journal, pp. 147-160, 2015. [Online]. Available: http://citeseerx.ist.psu.edu/viewdoc/download?doi=10.1.1.965.1767\&rep= rep1\&type=pdf. [Accessed: January 2020].

[19] M. S. Islam, S. Sultana, M. Saifunnahar, M. Miah, "Adaptation of Char livelihood on flood and river erosion areas through indigenous practice: A study on Bhuapur Riverine area in Tangail," Journal of Environmental Science and Natural Resources, vol. 7, no. 1, pp. 13-19, 2015. [Online]. Available: https://doi.org/10.3329/jesnr.v7i1.22138. [Accessed: January 2020].

[20] R. B. Bhandari, "Social capital in disaster risk management: a case study of social capital mobilization following the 1934 Kathmandu Valley earthquake in Nepal," Disaster Prevention and Management, vol. 23, no. 4, pp. 314-328, 2014. [Online]. Available: https://doi.org/10.1108/DPM-06-2013-0105. [Accessed: January 2020].

[21] P. D. Nunn, W. Aalbersberg, S. Lata, and M. Gwilliam, "Beyond the core: Communitygovernance for climate-change adaptation in peripheral parts of Pacific Island countries," Regional Environmental Change, vol. 14, pp. 221-235, 2014. [Online]. Available: https://doi.org/10.1007/s10113-013-0486-7. [Accessed: January 2020].

[22] S. Lambert, "Post-disaster indigenous mental health support: Tangata whaiora networks after the 2010-2012 Otautahi/ Christchurch earthquakes," MAI Journal, vol. 5, no. 1, pp. 76-91, 
2016. [Online]. Available: https://doi.org/10.20507/MAIJournal.2016.5.1.6. [Accessed: January 2020].

[23] L. -R Wang, S. Chen, and J. Chen, "Community resilience after disaster in Taiwan: A case study of Jialan village with the strengths perspective," Journal of Social Work in Disability \& Rehabilitation, vol. 12, no. 1-2, pp. 84-101, 2013. [Online]. Available: https://doi.org/10.1080/ 1536710X.2013.784551. [Accessed: January 2020].

[24] S. Vincze, Research Methodology. University of Debrecen, 2013.

[25] REACH-Initiative, "A study on knowledge, attitudes and practices (KAP) for disaster risk, reduction," in Northern Rakhine State, 2015. [Online]. Available: https://reliefweb.int/ report/myanmar/myanmar-assessment-report-study-knowledge-attitudes-and-practices-kapdisaster-risk. [Accessed: January 2020].

[26] P. Cochran, O. H. Huntington, C. Pungowiyi, S. Tom, F. S. Chapin III, H. P. Huntington, N. G. Maynard, and S. F. Trainor, "Indigenous frameworks for observing and responding to climate change in Alaska," in Maldonado, J.K., Colombi, B., \& Pandya R. (eds) Climate Change and Indigenous Peoples in the United States, Springer, Cham, pp. 49-59, 2013. [Online]. Available: https://doi. org/10.1007/978-3-319-05266-3_5. [Accessed: January 2020].

[27] V. Jha, and A. Jha, "Traditional knowledge on disaster management: A preliminary study of the Lepcha Community of Sikkim, India," Indian Journal of Traditional Knowledge, vol. 10, no. 1, pp. 173-182, 2011. [Online]. Available: http://hdl.handle.net/123456789/11078. [Accessed: January 2020].

[28] J. N. Nkem, O. A. Somorin, C. Jum, M. E. Idinoba, Y. M. Bele, and D. J. Sonwa, "Profiling climate change vulnerability of forest indigenous communities in the Congo basin," Mitigation and Adaptation Strategies for Global Change, vol. 18, pp. 513-533, 2013. [Online]. Available: https://doi.org/10. 1007/s11027-012-9372-8. [Accessed: January 2020].

[29] D. C. Israel and R. M. Briones, "Disaster, poverty, and coping strategies: The framework and empirical evidence from micro/household data-Philippine case," PIDS Discussion Paper Series, June 2014. [Online]. Available: http://hdl.handle.net/10419/126967. [Accessed: January 2020].

[30] G. Tuladhar, R. Yatabe, R. K. Dahal, and N. P. Bhandary, "Disaster risk reduction knowledge of local people in Nepal," Geoenvironmental Disasters, vol. 2, no. 5, 2015. [Online]. Available: https://doi.org/ 10.1186/s40677-014-0011-4. [Accessed: January 2020].

[31] J. M. R. Asio, "Disaster management program compliance and problems encountered in two provinces in Central Luzon, Philippines," Interdisciplinary Research Review, vol. 15, no. 5, pp. 24-31, 2020.

[32] M. N. Huda, "Understanding indigenous people's perception on climate change and climatic hazards: a case study of Chakma indigenous communities in Rangamati Sadar Upazila of Rangamati District, Bangladesh," Natural Hazards, vol. 65, pp. 2147-2159, 2013. [Online]. Available: https://doi.org/ 10.1007/s11069-012-0467-z. [Accessed: January 2020].

[33] D. Rogayan and L. Dollete, "Disaster awareness and preparedness of barrio community in Zambales, Philippines: Creating a baseline for curricular inteegration and extension program," Review of International Geographical Education Online, vol. 10, no. 2, pp. 92-114, 2020. [Online]. Available: https://doi.org/ 10.33403/rigeo.634564. [Accessed: January 2020]. 